\title{
Mechanism of lumen enlargement with direct stenting versus predilatation stenting: influence of remodelling and plaque characteristics assessed by volumetric intracoronary ultrasound
}

\author{
G Finet, N J Weissman, G S Mintz, L F Satler, K M Kent, J R Laird, G A Adelmann, \\ A E Ajani, M T Castagna, G Rioufol, A D Pichard
}

See end of article for authors' affiliations

Correspondence to: Professor Gérard Finet, Department of Haemodynamics, Cardiovascular Hospital and Claude Bernard University, 69394 Lyon Cedex 03, France; gerard.finet@ creatis. univ-lyon 1 .fr

Accepted 21 May 2002

\begin{abstract}
Objective: To compare the effects of arterial remodelling and plaque characteristics on the mechanisms of direct stenting and predilatation stenting. Direct stenting has become routine in some laboratories and differs technically from predilatation stenting.

Methods: Pre- and post-interventional volumetric intravascular ultrasound (IVUS) was undertaken in 30 patients with direct stenting and in 30 with predilatation stenting of non-calcified native coronary lesions, using the same stent design and stent length. Lumen, vessel (external elastic membrane (EEM)), and plaque (plaque + media) volumes were calculated. Remodelling was determined by comparing the EEM area at the centre of the lesion with the EEM areas at proximal and distal reference sites. Plaque eccentricity was defined as the thinnest plaque diameter to the thickest plaque diameter ratio. Plaque composition was characterised as soft, mixed, or dense.

Results: All volumetric IVUS changes were similar in the two groups. Pre-intervention remodelling remained uninfluenced after direct stenting, but was neutralised after predilatation stenting. Eccentric lesions responded to intervention by a greater luminal gain owing to greater vessel expansion in direct stenting. Plaque composition influenced luminal gain in direct stenting, the gain being greatest in the softest plaques; in predilatation stenting, luminal gain was equivalent but vessel expansion was greater for "dense" plaque and plaque reduction greater for "soft" plaque.

Conclusions: In non-calcified lesions, the mechanisms of lumen enlargement after direct or predilatation stenting are significantly influenced by atherosclerotic remodelling, plaque eccentricity, and plaque composition.
\end{abstract}

$\mathrm{P}$ laque morphology and composition (for example, the calcium content of the plaque) alter the success of lumen enlargement by balloon angioplasty and stenting. ${ }^{12}$ Coronary atherosclerotic remodelling also influences the mechanism of lumen enlargement after balloon angioplasty. ${ }^{3}$ However, direct stenting without previous balloon predilatation has now become widely accepted. ${ }^{45}$ Direct stenting has become routine in some laboratories and differs technically from predilatation stenting. ${ }^{67}$ The influence of arterial remodelling and plaque morphology and composition on the success rate or the mechanism of lumen enlargement with direct stenting remains unknown.

The purpose of this three dimensional volumetric intravascular ultrasound (IVUS) study is to analyse the influence of atherosclerotic coronary remodelling and plaque characteristics during direct stenting compared with predilatation stenting.

\section{METHODS}

\section{Patient and lesion population}

To assess the effect of plaque morphology and vascular remodelling on stents placed with or without balloon predilatation, we carried out a retrospective study of 60 patients with non-ostial, non-calcified, de novo native coronary artery lesions, using the same stent design (ACS Multilink Duet or Tristar stent, Guidant Corp, Santa Clara, California, USA) and the same stent length $(13 \mathrm{~mm})$. Among these 60 patients, two groups were defined: a group of 30 patients treated by direct stenting, and a group of 30 patients treated by predilatation stenting. The decision whether or not to predilate was partly based on the attitudes of the operator. All lesions in both groups met the main inclusion criterion that pre-intervention IVUS examination should be physically feasible. Consequently, the direct stenting success rate was $100 \%$.

For each procedure, the maximum balloon inflation pressure and the diameter of the stent used were recorded. Vessel overstretch was assessed by calculating the stent to artery ratio. This ratio was defined as the real diameter of the stent used divided by the mean IVUS reference diameter. The real diameter of the stent was defined as the diameter of the Multilink Duet or Tristar stent at the maximum balloon pressure for each angioplasty, according to the balloon compliance table provided by Guidant Corp (the linear compliance curve of the balloon). All lesions were treated with a single stent without previous atheroablation.

\section{IVUS imaging protocol}

Lesions were examined by pre- and post-intervention IVUS after the administration of $200 \mu \mathrm{g}$ of intracoronary glyceryl trinitrate. Pre-intervention analysis was performed before balloon predilatation in the predilatation stenting group. In both groups, post-intervention analysis was done as the final step in the procedure. The IVUS system used was a commercially available mechanical sector scanner (Cardiovascular

Abbreviations: CSA, cross sectional area; EEM, external elastic membrane; IVUS, intravascular ultrasound; $P+M$, plaque + media 
Imaging Systems Inc, Sunnyvale, California, USA) with single element ultrasound catheters (Ultracross 3.5 French at $30 \mathrm{MHz}$ and Discovery 2.6 French at $40 \mathrm{MHz}$; Boston Scientific Corp, Watertown, Massachusetts, USA). The transducer was advanced more than $10 \mathrm{~mm}$ distally to the lesion. The artery was imaged in retrograde, using a motorised pullback at $0.5 \mathrm{~mm} / \mathrm{s}$, over the whole lesion and proximal reference segment.

\section{Quantitative angiographic analysis}

Quantitative coronary angiography was undertaken using computer assisted automated edge detection (CMS-MEDIS). Calibration was performed from the external diameter of the contrast filled guiding catheter. Reference and lesion minimum lumen diameter were measured before and after stent implantation.

\section{Three dimensional IVUS analysis}

All analysed IVUS images were digitised from S-VHS video tape with $256 \times 256$ pixels. IVUS images with artefacts such as non-uniform or geometric distortion were rejected. ${ }^{89}$ Using the clock on the videotape and knowing the pullback speed $(0.5 \mathrm{~mm} / \mathrm{s})$, we identified three vessel segments from the post-intervention IVUS imaging: the stented segment ( $13 \mathrm{~mm}$ long); a $5 \mathrm{~mm}$ long proximal reference segment; and a $5 \mathrm{~mm}$ long distal reference segment. Thus the total length of the artery analysed was $23 \mathrm{~mm}$. With the use of reproducible landmarks (for example, a calcium deposit or a side branch), we defined the same arterial segments on the pre-intervention IVUS imaging run. Each pre-intervention segment that corresponded to the stented segment on the post-intervention IVUS imaging run was precisely centred, such that the centre of the pre-intervention "stent" segment was centred on the post-interventional stent (fig l).

We used a novel three dimensional volumetric IVUS software (IôDP, Data Processing, Paris, France) to analyse vessel reconstruction. For each motorised pullback at $0.5 \mathrm{~mm} / \mathrm{s}$, 50 IVUS images were digitised every millimetre for a total of $23 \mathrm{~mm} \times 50$ images (= 1150 IVUS images per imaging run). The XY calibration was 157 pixels $/ 8 \mathrm{~mm}$; consequently we obtained $(157 \times 23) / 8=451$ slices for a $23 \mathrm{~mm}$ long vascular segment of interest. The software would then suppress some slices in order to get an isotropic volume (that is, isotropic voxels). Using an interactive system based on a uniform B spline, we obtained two contours corresponding to the lumen and the external elastic membrane. ${ }^{10}$ These contours were traced on approximately 40 cross sectional image slices evenly distributed along the vascular segment, taking care to identify consistent images with respect to dynamic changes during the cardiac cycle, cardiac motion, and IVUS catheter movement. ${ }^{11}$ An axial automatic propagation algorithm then determined the best fitted surface shape. This resulted in a total of 451 cross sectional images quantified for lumen cross sectional area (CSA) $\left(\mathrm{mm}^{2}\right)$, external elastic membrane (EEM) CSA $\left(\mathrm{mm}^{2}\right)$, and plaque + media $(\mathrm{P}+\mathrm{M}) \mathrm{CSA}\left(\mathrm{mm}^{2}\right)$. Volumetric data were calculated using the formula:

$$
V=\Sigma_{t=1}{ }^{t=451} A_{i} * T
$$

where $\mathrm{V}=$ volume, $\mathrm{A}=$ area of lumen or EEM, and $\mathrm{T}=$ thickness of each cross sectional image slice $(0.05 \mathrm{~mm})$. Lumen, vessel, and plaque volumes (lumen, EEM, P+M vol; $\mathrm{mm}^{3}$ ) were determined.

Validation of cross sectional and axial IVUS analyses has been reported. ${ }^{1}$ Three dimensional reconstructions and views were generated, taking into account the problems associated with catheter displacements that inevitably occur during automatic pull back. ${ }^{12}{ }^{13}$ For visualisation of the arterial segment, a surface rendering algorithm (shading) was used to explore overall morphological changes in the atherosclerotic lesions.
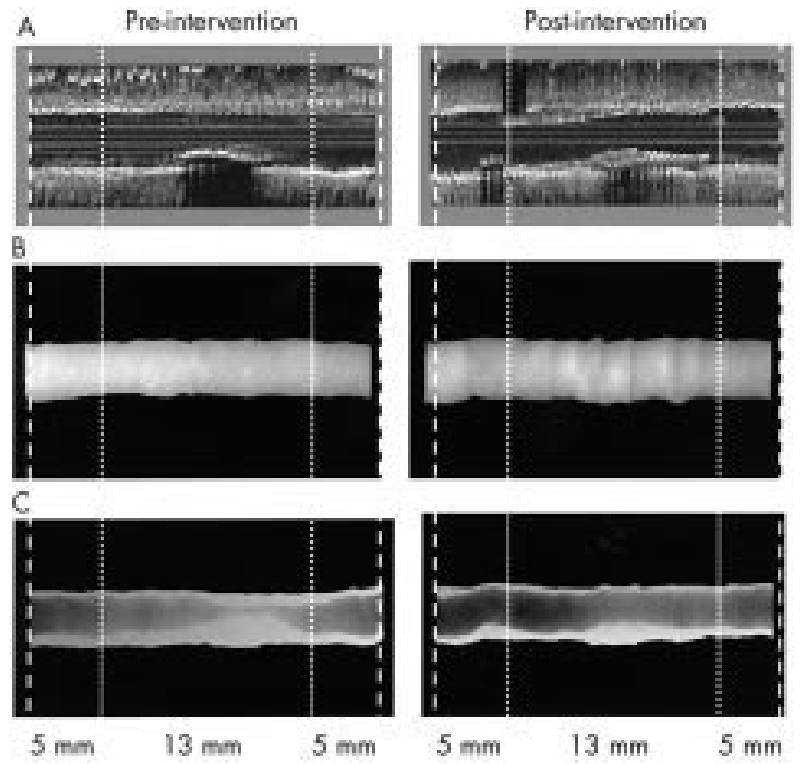

Figure 1 Representation of the method. Stent strut hypereflectivity allowed precise localisation of the proximal and distal extremities. Two $5 \mathrm{~mm}$ long proximal and distal reference segments were determined on both sides of the stent. Thus the total length of the analysed arterial segment was $23 \mathrm{~mm}$ for the 60 studied lesions (30 treated by direct stenting and 30 treated by predilatation stenting) (panel A, three dimensional reformatting). A similar $23 \mathrm{~mm}$ long segment was then determined on the pre-intervention imaging run, using precise landmarks. Volumetric analysis was done using intravascular ultrasound (IVUS) in 451 slices of $0.05 \mathrm{~mm}$ thickness. Three dimensional IVUS representations were generated by a specific digital image processing, using contour segmentation and surface rendering: $(B)$ vessel volume (external elastic membrane $(E E M)) ;(C)$ plaque (plaque + media $(P+M))$ and lumen volumes.

\section{Accuracy and reproducibility of three dimensional volumetric IVUS analysis}

The three dimensional volumetric IVUS analysis was validated using a $536 \mathrm{~mm}^{3}$ multicylindric acrylic phantom model. The accuracy of this technique was $-2.1 \%$, with a variability of $\pm 3.2 \%$. The mean (SD) intraobserver differences of lumen volume and EEM volume were $4.2(6.3) \mathrm{mm}^{3}$ and $4.04(6.7) \mathrm{mm}^{3}$, respectively, yielding a relative intraobserver variability of 2.4 $(4.1) \%$ and $1.05(1.8) \%$, with an excellent correlation $\left(r^{2}=0.98\right.$ and $\left.0.99, \mathrm{p}<0.001 ; \mathrm{n}=20\right)$.

Post hoc in vivo validation was undertaken by two skilled operators (GF, GR) in a randomly selected group of lesions $(n=20)$ testing intraobserver and interobserver variability of lumen volume $(2.2 \%$ and $2.7 \%$, respectively) and EEM volume $(2.6 \%$ and $3.2 \%)$. In addition, validation of IVUS length measurements was done on this known $13 \mathrm{~mm}$ long stent. The stent length of the MultiLink/Duet-Tristar stent, after correction for the foreshortening effect of stent expansion $(2.5 \%$, provided by Guidant Corporation), is $12.68 \mathrm{~mm}$. The mean (SD) IVUS length in this study was $12.86(0.58) \mathrm{mm}$ (the mean difference was $+0.18 \mathrm{~mm}$ or $+1.42 \%$ ).

\section{IVUS definitions}

- Lumen and EEM IVUS references were defined by calculating the averaged cross sectional areas in the first $1 \mathrm{~mm}$ long proximal and the last $1 \mathrm{~mm}$ long distal reference segments.

- The centre of the lesion was defined as the smallest pre-intervention lumen cross sectional area.

- Remodelling was considered to be an intrinsic atherosclerotic change in the lesion morphology. The remodelling ( $\mathrm{R})$ ratio was determined by comparing the EEM area at the centre of the lesion with the average of the mean EEM area 
Table 1 Patient and target lesion before coronary interventions

\begin{tabular}{llll}
\hline & $\begin{array}{l}\text { Direct } \\
\text { stenting } \\
(n=30)\end{array}$ & $\begin{array}{l}\text { Predilation } \\
\text { stenting } \\
(n=30)\end{array}$ & p Value \\
\hline Vessel treated & $13(43 \%)$ & $15(50 \%)$ & NS \\
LAD & $9(30 \%)$ & $7(23 \%)$ & NS \\
LCx & $8(27 \%)$ & $8(27 \%)$ & NS \\
RCA & $3.05(0.5)$ & $2.82(0.4)$ & 0.08 \\
IVUS mean diameter reference (mm) & $3.62(2.3)$ & $3.64(3.2)$ & NS \\
Plaque eccentricity ratio & $17(57 \%)$ & $12(41 \%)$ & NS \\
Plaque composition & $8(27 \%)$ & $13(43 \%)$ & NS \\
$\quad$ Soft & $5(16 \%)$ & $5(16 \%)$ & NS \\
$\quad$ Heterogeneous & $-5.2(25)$ & $0.8(35)$ & NS \\
$\quad$ Dense & 9 & 12 & NS \\
Mean remodelling ratio & 21 & 18 & 0.02 \\
Positive remodelling (n) & $1.9(0.7)$ & $3.9(1.1)$ & $<0.001$ \\
Negative remodelling (n) & $3.48(0.4)$ & $3.23(0.4)$ & 0.02 \\
Number of balloon inflations & $15.13(3.18)$ & $12.4(2.35)$ & 0.001 \\
Mean diameter of stent used (mm) & $1.24(0.13)$ & $1.23(0.17)$ & NS \\
Maximum BIP (atm) & & & \\
Stent/artery ratio & & &
\end{tabular}

Values are mean (SD) unless stated.

BIP, balloon inflation pressure; IVUS, intravascular ultrasound; LAD, left anterior descending coronary artery; LCx, left circumflex coronary artery; RCA, right coronary artery.

at the first $1 \mathrm{~mm}$ long proximal and the last $1 \mathrm{~mm}$ long distal references: positive $\mathrm{R}(+\mathrm{R})$ was defined as a relative ratio $=0 \%$ and negative $\mathrm{R}(-\mathrm{R})$ is $<0 \%$.

- The acute change in lesion morphology secondary to the interventional procedure was described by the ratio of lesion/reference EEM after stent implantation. The postintervention reference EEM was used for the calculation of this ratio. Positive lesion/reference EEM after stent implantation was defined as a relative ratio $=0 \%$ and negative lesion/reference EEM after stent implantation was $<0 \%$.

- Plaque eccentricity (ECC) was identified when the thinnest plaque diameter to the thickest plaque diameter ratio was $<0.5$.

- Plaques are characterised by their appearance on IVUS images. (1) Echolucent ("soft"): lesion echogenicity less than that of the surrounding adventitia for more than $80 \%$ of the plaque area (loose fibrous plaque with lipid or cellular pool or deposition). (2) Echodense ("hard"): lesion echogenicity greater than that of the surrounding adventitia for more than $80 \%$ of the plaque area (dense fibrous plaque). (3) Heterogeneous ("mixed"): the presence of echodense and echolucent regions within the plaque, all being less than $80 \%$ of the plaque area (varying degrees of loose and dense fibrous plaque). ${ }^{14}$

- Lesions containing $>45^{\circ}$ of circumferential calcium were excluded.
Table 3 Comparative volumetric intravascular ultrasound measurements

\begin{tabular}{llll}
\hline & $\begin{array}{l}\text { Direct stenting } \\
(\mathrm{n}=30)\end{array}$ & $\begin{array}{l}\text { Predilation stenting } \\
(\mathrm{n}=30)\end{array}$ & \\
\cline { 2 - 3 } & Change $\left(\mathrm{mm}^{3}\right)$ & Change $\left(\mathrm{mm}^{3}\right)$ & $\mathrm{p}$ Value \\
\hline Total length $(23 \mathrm{~mm})$ & & & \\
Lumen volume & $58.0(25.2)$ & $58.4(35.5)$ & 0.79 \\
EEM volume & $38.8(28.7)$ & $40.6(34.8)$ & 0.85 \\
$\mathrm{P}+\mathrm{M}$ volume & $-19.2(18.7)$ & $-17.8(17.6)$ & 0.51 \\
\hline
\end{tabular}

Values are mean (SD). Changes are $\Delta$ pre-post intervention values. $E E M$, external elastic membrane; $P+M$, plaque plus media.

\section{Statistical analysis}

Statistical analysis was performed using StatView 4.5 statistical software (Abacus Concept, Berkeley, California, USA). Continuous data are presented as mean (SD), and categorial data as frequencies. Comparison between post- and preintervention measurements was done using a two tailed paired $t$ test. Comparison of measurements between direct stenting and predilatation stenting groups was done using the unpaired Student $t$ test. A probability value of $\mathrm{p}=0.05$ was considered significant.

\section{RESULTS}

\section{Baseline findings}

Thirty lesions were treated by direct stenting and 30 by predilatation stenting. Baseline demographics and target lesion characteristics in the two groups are shown in table 1. IVUS mean reference diameter was marginally larger in the direct stenting group, and the mean stent diameter was greater. There was a significant difference between maximum balloon inflation pressure and the number of inflations. The calculated stent to artery ratio was similar in the two groups (1.24 (0.13) v $1.23(0.17), \mathrm{p}=0.91)$. After stent deployment, additional balloon inflations with another balloon in order to optimise stent implantation were undertaken in 36\% of cases for the direct stenting group and $28 \%$ for the predilatation stenting group. Pre- and post-intervention coronary angiography and IVUS measurement results are shown in table 2 .

\section{Changes in plaque morphology}

Comparisons of volumetric IVUS measurements between the direct stenting and predilatation stenting groups are summarised in table 3. Absolute luminal gain was similar in both groups, with an increase in luminal volume of approximately $54 \%$ after implantation of the stent. Over the $23 \mathrm{~mm}$ length of the analysed arterial segments, the mean increase in luminal volume was $58 \mathrm{~mm}^{3}$. The stent induced vessel expansion was similar in both the direct stenting and the predilatation stenting groups and accounted for $67 \%$ of the luminal gain.

Table 2 Pre- and post-intervention coronary angiography and intravascular ultrasound measurements

\begin{tabular}{|c|c|c|c|c|c|c|}
\hline & \multicolumn{3}{|l|}{ Direct stenting } & \multicolumn{3}{|c|}{ Predilatation stenting } \\
\hline & Pre-intervention & Post-intervention & $\mathrm{p}$ Value & Pre-intervention & Post-intervention & $\mathrm{p}$ Value \\
\hline \multicolumn{7}{|l|}{ QCA } \\
\hline Proximal reference diameter $(\mathrm{mm})$ & $3.25(0.5)$ & $3.3(0.47)$ & 0.37 & $2.98(0.49)$ & $3.11(0.46)$ & 0.42 \\
\hline Minimum lumen diameter (mm) & 1.02 (0.39) & $3.19(0.4)$ & $<0.0001$ & $0.96(0.38)$ * & $2.96(5.4)$ & $<0.0001$ \\
\hline Diameter stenosis (\%) & $68.5(12.2)$ & $3.3(5.9)$ & $<0.0001$ & 74.43 (11.97) & $4.8(4.2)$ & $<0.0001$ \\
\hline \multicolumn{7}{|l|}{ IVUS } \\
\hline Lumen volume $\left(\mathrm{mm}^{3}\right)$ & $126.9(46.9)$ & $187.1(49.1)$ & $<0.0001$ & $111.1(44.5)$ & $169.5(52.1)$ & $<0.0001$ \\
\hline EEM volume $\left(\mathrm{mm}^{3}\right)$ & $304.0(97.7)$ & $342.8(101.4)$ & $<0.0001$ & $296.8(104.7)$ & $337.4(115.2)$ & $<0.0001$ \\
\hline$P+M$ volume $\left(\mathrm{mm}^{3}\right)$ & $177.0(59.1)$ & $155.7(59.7)$ & $<0.0001$ & $185.7(74.5)$ & $167.9(70.8)$ & $<0.0001$ \\
\hline
\end{tabular}

Values are mean (SD).

*NS $v$ preintervention direct stenting minimum lumen diameter.

EEM, external elastic membrane; IVUS, intravascular ultrasound; $P+M$, plaque plus media; $Q C A$, quantitative coronary angiography. 


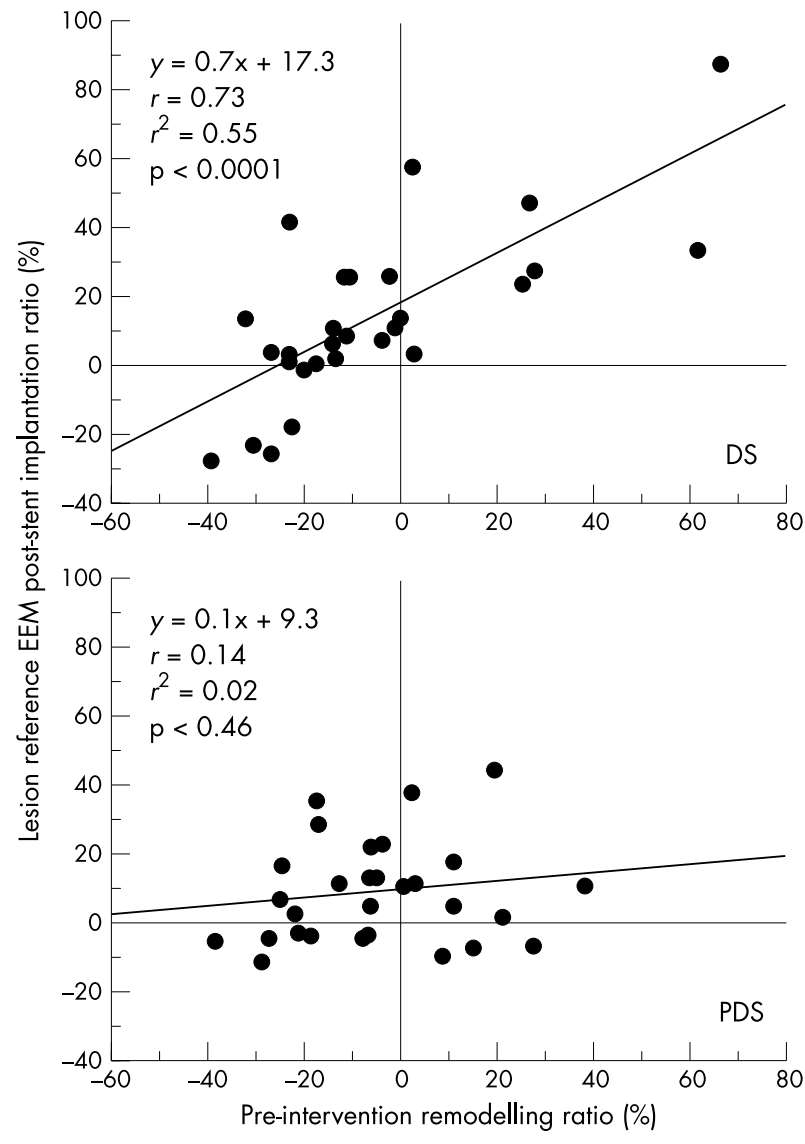

Figure 2 Influence of the pre-intervention atherosclerotic remodelling ratio on the post-intervention remodelling ratio after direct and indirect stent implantation. The pre-intervention remodelling ratio remained uninfluenced after direct stenting (DS), but was neutralised after predilatation stenting (PDS).

Similarly, plaque reduction was equivalent in both groups and accounted for $33 \%$ of the luminal gain. The mean plaque reduction was $18 \mathrm{~mm}^{3}$.
Influence of arterial remodelling on changes in plaque morphology

Atherosclerotic arterial remodelling was more often negative in both the groups.

Direct stenting

In the direct stenting group, there was no change in the remodelling ratio (that is, if there was positive remodelling before direct stenting then positive remodelling was seen after direct stenting, and vice versa). Mathematically, this is demonstrated by a high correlation between the preintervention remodelling ratio and the calculated post-direct stenting remodelling ratio $(\mathrm{y}=0.7 \mathrm{x}+17.3, \quad r=0.73$, $\mathrm{p}<0.0001$ ). Luminal gain appeared to be significantly greater in cases of pre-interventional positive remodelling (72.9 (29.5) $\mathrm{mm}^{3} v 51.62(20.6) \mathrm{mm}^{3}, \mathrm{p}=0.03$ ) with direct stenting. This luminal gain is the result of the greater vessel expansion (52.35 (26.7) $\left.\mathrm{mm}^{3} v 33.45(16.5) \mathrm{mm}^{3}, \mathrm{p}=0.04\right)$.

\section{Predilatation stenting}

In the predilatation stenting group, the effect of atheromatous remodelling observed with the pre-intervention lesion was neutralised (that is, if there was positive remodelling before stenting, then no remodelling was noted after predilatation stenting; $p=0.46$ for pre- $v$ postremodelling ratio). While there was no difference in luminal gain with either positive or negative remodelling, predilatation stenting caused a greater plaque reduction with positive remodelling $\left(-23.81(81) \mathrm{mm}^{3} \mathrm{v}\right.$ $\left.-13.82(6.1) \mathrm{mm}^{3}, \mathrm{p}=0.03\right)$ and a trend towards larger vessel expansion with negative remodelling $\left(46.57\right.$ (21.6) $\mathrm{mm}^{3} v$ $31.58(16.3) \mathrm{mm}^{3}, \mathrm{p}=0.08$ ) (fig 2 and table 4 ).

\section{Influence of lesion eccentricity on mechanisms of lumen enlargement}

Lesion eccentricity influenced the mechanism of lumen enlargement. In the direct stenting group, a similar trend toward greater lumen enlargement in eccentric lesions was noted but did not reach significance (table 5 ).

In the predilatation stenting group, this influence was significant: there was a greater luminal gain (69.64 (33.8) $\left.\mathrm{mm}^{3} v 47.85(26.4) \mathrm{mm}^{3}, \mathrm{p}=0.04\right)$ induced by a greater vessel expansion $\left(50.41 \quad(18.5) \mathrm{mm}^{3} v 31.19 \quad(13.9) \mathrm{mm}^{3}\right.$, $\mathrm{p}=0.01)$ in eccentric lesions.

\begin{tabular}{|c|c|c|c|c|c|c|}
\hline & \multicolumn{3}{|c|}{ Direct stenting $(n=30)$} & \multicolumn{3}{|c|}{ Predilatation stenting $(n=30)$} \\
\hline & $+R$ & $-R$ & $\mathrm{p}$ Value & $+R$ & $-R$ & $\mathrm{p}$ Value \\
\hline$n(\%)$ & $9(30)$ & $21(70)$ & & $12(40)$ & $18(60)$ & \\
\hline \multicolumn{7}{|c|}{ Proximal reference $(5 \mathrm{~mm})$} \\
\hline Lumen volume $\left(\mathrm{mm}^{3}\right)$ & $1.8(4.1)$ & $3.7(1.7)$ & 0.28 & $3.2(6.1)$ & $4.2(7.9)$ & 0.69 \\
\hline EEM volume $\left(\mathrm{mm}^{3}\right)$ & $5.2(7.4)$ & $1.1(3.8)$ & 0.03 & $-0.5(8.5)$ & $2.7(8.7)$ & 0.33 \\
\hline $\mathrm{P}+\mathrm{M}$ volume $\left(\mathrm{mm}^{3}\right)$ & $3.4(6.1)$ & $-2.9(4.0)$ & 0.02 & $-3.6(7.9)$ & $-1.5(5.3)$ & 0.38 \\
\hline \multicolumn{7}{|l|}{ Stent $(13 \mathrm{~mm})$} \\
\hline Lumen volume $\left(\mathrm{mm}^{3}\right)$ & $61.9(25.2)$ & $44.6(13.8)$ & 0.02 & $46.2(21.8)$ & $49.8(25.1)$ & 0.69 \\
\hline EEM volume $\left(\mathrm{mm}^{3}\right)$ & $41.8(27.1)$ & $30.4(14.6)$ & 0.14 & $25.4(18.3)$ & $39.00(27.7)$ & 0.14 \\
\hline $\mathrm{P}+\mathrm{M}$ volume $\left(\mathrm{mm}^{3}\right)$ & $-20.1(14.8)$ & $-14.1(11.0)$ & 0.22 & $-20.8(18.2)$ & $-10.8(13.3)$ & 0.09 \\
\hline \multicolumn{7}{|l|}{ Distal reference $(5 \mathrm{~mm})$} \\
\hline Lumen volume $\left(\mathrm{mm}^{3}\right)$ & $9.2(8.0)$ & $3.3(7.5)$ & 0.06 & $6.1(6.9)$ & $6.4(6.3)$ & 0.88 \\
\hline EEM volume $\left(\mathrm{mm}^{3}\right)$ & $4.3(7.4)$ & $2.2(8.6)$ & 0.52 & $6.7(7.6)$ & $4.9(6.4)$ & 0.48 \\
\hline $\mathrm{P}+\mathrm{M}$ volume $\left(\mathrm{mm}^{3}\right)$ & $-4.8(6.5)$ & $-1.1(4.2)$ & 0.07 & $0.6(1.8)$ & $-1.5(4.1)$ & 0.10 \\
\hline \multicolumn{7}{|l|}{ Total length $(23 \mathrm{~mm})$} \\
\hline Lumen volume $\left(\mathrm{mm}^{3}\right)$ & $72.9(29.5)$ & $51.6(20.6)$ & 0.03 & $55.4(31.3)$ & $60.4(34.0)$ & 0.68 \\
\hline EEM volume $\left(\mathrm{mm}^{3}\right)$ & $52.4(26.7)$ & $33.5(16.5)$ & 0.04 & $31.6(16.3)$ & $46.6(21.6)$ & 0.08 \\
\hline $\mathrm{P}+\mathrm{M}$ volume $\left(\mathrm{mm}^{3}\right)$ & $-21.6(22.5)$ & $-18.2(13.1)$ & 0.60 & $-23.8(81.0)$ & $-13.8(6.1)$ & 0.03 \\
\hline
\end{tabular}

Values are mean (SD).

$E E M$, external elastic membrane; $P+M$, plaque plus media; $+R /-R$, positive/negative remodelling. 
Table 5 Influence of plaque eccentricity on mechanisms of lumen enlargement

\begin{tabular}{|c|c|c|c|c|c|c|}
\hline & \multicolumn{3}{|c|}{ Direct stenting $(n=30)$} & \multicolumn{3}{|c|}{ Predilatation stenting $(n=30)$} \\
\hline & EEC & No ECC & $\mathrm{p}$ Value & ECC & No ECC & $\mathrm{p}$ Value \\
\hline$n(\%)$ & $22(73)$ & $8(26)$ & & $17(57)$ & $13(43)$ & \\
\hline \multicolumn{7}{|c|}{ Proximal reference $(5 \mathrm{~mm})$} \\
\hline Lumen volume $\left(\mathrm{mm}^{3}\right)$ & $4.1(3.3)$ & $2.8(4.7)$ & 0.52 & $4.0(6.9)$ & $1.0(6.0)$ & 0.06 \\
\hline EEM volume $\left(\mathrm{mm}^{3}\right)^{2}$ & $0.8(3.2)$ & $2.5(5.9)$ & 0.47 & $1.4(5.3)$ & $-0.5(3.9)$ & 0.13 \\
\hline$P+M$ volume $\left(\mathrm{mm}^{3}\right)$ & $-3.2(1.6)$ & $-0.3(5.7)$ & 0.22 & $-2.6(6.6)$ & $-1.5(4.5)$ & 0.38 \\
\hline \multicolumn{7}{|l|}{ Stent $(13 \mathrm{~mm})$} \\
\hline Lumen volume $\left(\mathrm{mm}^{3}\right)$ & $58.2(21.2)$ & $44.2(12.3)$ & 0.10 & $56.2(22.6)$ & $41.1(21.7)$ & 0.03 \\
\hline EEM volume $\left(\mathrm{mm}^{3}\right)$ & $42.5(21.3)$ & $31.2(12.4)$ & 0.12 & $41.4(17.0)$ & $30.4(27.2)$ & 0.05 \\
\hline $\mathrm{P}+\mathrm{M}$ volume $\left(\mathrm{mm}^{3}\right)$ & $-12.7(13.7)$ & $-13.0(5.8)$ & 0.58 & $-14.9(12.6)$ & $-10.7(18.2)$ & 0.76 \\
\hline \multicolumn{7}{|l|}{ Distal reference $(5 \mathrm{~mm})$} \\
\hline Lumen volume $\left(\mathrm{mm}^{3}\right)$ & $5.2(8.2)$ & $4.9(7.8)$ & 0.93 & $9.5(7.5)$ & $4.1(4.6)$ & 0.02 \\
\hline EEM volume $\left(\mathrm{mm}^{3}\right)$ & $3.2(7.7)$ & $1.9(10.3)$ & 0.42 & $8.8(8.9)$ & $3.5(4.0)$ & 0.03 \\
\hline$P+M$ volume $\left(\mathrm{mm}^{3}\right)$ & $-2.0(5.1)$ & $-3.0(5.6)$ & 0.67 & $-0.6(4.4)$ & $-0.7(2.9)$ & 0.97 \\
\hline \multicolumn{7}{|l|}{ Total length $(23 \mathrm{~mm})$} \\
\hline Lumen volume $\left(\mathrm{mm}^{3}\right)$ & $67.4(27.6)$ & $52.0(19.8)$ & 0.11 & $69.6(33.8)$ & $47.9(26.4)$ & 0.04 \\
\hline EEM volume $\left(\mathrm{mm}^{3}\right)$ & $46.5(24.5)$ & $35.6(21.8)$ & 0.14 & $50.4(18.5)$ & $31.2(13.9)$ & 0.01 \\
\hline $\mathrm{P}+\mathrm{M}$ volume $\left(\mathrm{mm}^{3}\right)$ & $-17.9(16.7)$ & $-16.3(21.7)$ & 0.65 & $-19.1(14.5)$ & $-16.7(20.3)$ & 0.71 \\
\hline
\end{tabular}

Table 6 Influence of plaque composition on mechanisms of lumen enlargement

\begin{tabular}{|c|c|c|c|c|c|c|}
\hline & \multicolumn{3}{|c|}{ Direct stenting $(n=30)$} & \multicolumn{3}{|c|}{ Predilatation stenting $(n=30)$} \\
\hline & Soft & Mixed & Dense & Soft & Mixed & Dense \\
\hline n $(\%)$ & $17(57)$ & $8(26)$ & $5(17)$ & $12(40)$ & $13(43)$ & $5(17)$ \\
\hline \multicolumn{7}{|c|}{ Proximal reference $(5 \mathrm{~mm})$} \\
\hline Lumen volume $\left(\mathrm{mm}^{3}\right)$ & $0.1(5.5)$ & $4.2(3.7)$ & $4.3(2.7)$ & $4.0(7.0)$ & $2.6(7.7)$ & $5.0(7.1)$ \\
\hline EEM volume $\left(\mathrm{mm}^{3}\right)$ & $4.4(7.1)$ & $1.2(4.4)$ & $1.6(5.6)$ & $-5.1(10.0)$ & $0.9(8.0)$ & $4.8(7.8) \dagger$ \\
\hline $\mathrm{P}+\mathrm{M}$ volume $\left(\mathrm{mm}^{3}\right)$ & $4.3(4.9)$ & $-3.0(4.2)$ & $-2.7(5.2)$ & $-9.1(9.9)$ & $-1.8(5.4)$ & $-0.2(4.0) \dagger$ \\
\hline \multicolumn{7}{|l|}{ Stent $(13 \mathrm{~mm})$} \\
\hline Lumen volume $\left(\mathrm{mm}^{3}\right)$ & $56.8(23.2)$ & 49.4 (18.9) & $40.0(10.8)^{*}$ & $49.0(26.5)$ & $47.3(25.9)$ & $49.2(21.6)$ \\
\hline EEM volume $\left(\mathrm{mm}^{3}\right)$ & $34.3(19.3)$ & $34.4(22.1)$ & $30.4(10.9)$ & $27.3(18.2)$ & $31.7(20.2)$ & $38.1(18.4) \dagger$ \\
\hline $\mathrm{P}+\mathrm{M}$ volume $\left(\mathrm{mm}^{3}\right)$ & $-22.4(15.2)$ & $-14.7(11.1)$ & $-9.6(7.2)^{*}$ & $-21.7(16.6)$ & $-15.6(13.9)$ & $-11.1(9.2) \dagger$ \\
\hline \multicolumn{7}{|c|}{ Distal reference $(5 \mathrm{~mm})$} \\
\hline Lumen volume $\left(\mathrm{mm}^{3}\right)$ & $8.5(7.3)$ & $3.8(8.2)$ & $4.0(7.7)$ & $7.5(8.7)$ & $5.3(6.2)$ & $6.8(6.1)$ \\
\hline EEM volume $\left(\mathrm{mm}^{3}\right)$ & $4.1(3.7)$ & $2.4(9.6)$ & $2.5(9.5)$ & $5.9(7.7)$ & $5.2(7.1)$ & $5.9(6.7)$ \\
\hline$P+M$ volume $\left(\mathrm{mm}^{3}\right)$ & $-4.5(7.0)$ & $-1.4(4.7)$ & $-1.5(2.1)$ & $-1.6(6.1)$ & $-0.1(2.9)$ & $-0.9(3.0)$ \\
\hline \multicolumn{7}{|l|}{ Total length $(23 \mathrm{~mm})$} \\
\hline Lumen volume $\left(\mathrm{mm}^{3}\right)$ & $65.3(28.0)$ & $57.4(25.8)$ & $48.3(12.3)^{*}$ & 60.5 (35.9) & $55.4(31.4)$ & $61.0(28.3)$ \\
\hline EEM volume $\left(\mathrm{mm}^{3}\right)$ & $42.8(23.1)$ & $38.3(23.2)$ & 34.4 (22.7) & $28.2(19.2)$ & $37.8(21.3)$ & $48.8(21.2) \dagger$ \\
\hline $\mathrm{P}+\mathrm{M}$ volume $\left(\mathrm{mm}^{3}\right)$ & $-22.7(12.1)$ & $-19.1(13.9)$ & $-13.9(11.9)^{*}$ & $-32.3(12.7)$ & $-17.5(19.8)$ & $-12.2(8.4) \dagger$ \\
\hline
\end{tabular}

\section{Influence of plaque composition on mechanisms of lumen enlargement}

Plaque composition was evenly distributed in both groups.

\section{Direct stenting}

In the direct stenting group, the greatest luminal gain were noted in the softest plaques. There was a significant difference in luminal gain between soft and dense plaques (65.4 (28) $\left.\mathrm{mm}^{3} \vee 48.3(12.3) \mathrm{mm}^{3}, \mathrm{p}=0.02\right)$ owing to a greater plaque reduction in the soft plaques $\left(-22.69(12.1) \mathrm{mm}^{3} \mathrm{v}\right.$ -13.86 (11.9) $\mathrm{mm}^{3}, \mathrm{p}=0.04$ ).

\section{Predilatation stenting}

There were contrasting results in the predilatation stenting group. The luminal gain with predilatation stenting was not affected by plaque morphology (table 6). However, the mechanism of luminal gain was significantly different with differ- ent plaque types-thus vessel expansion was greater for dense plaque (48.79 (21.2) $\left.\mathrm{mm}^{3} v 28.17(19.2) \mathrm{mm}^{3}, \mathrm{p}<0.05\right)$ and plaque reduction was greater for soft plaque $\left(-32.3(12.7) \mathrm{mm}^{3}\right.$ $v-12.15(8.4) \mathrm{mm}^{3}, \mathrm{p}<0.05$ ) (table 6).

An example of three dimensional IVUS representations of plaque changes before and after intervention is shown in fig 3 .

\section{DISCUSSION}

In this study we describe and compare the influence of lesion characteristics on the mechanisms of lumen enlargement during direct and predilatation stenting. We showed the following. Firstly, volumetric changes in plaque were similar in the two groups. Secondly, pre-intervention atherosclerotic remodelling did not influenced direct stenting, but was neutralised after predilatation stenting. Thirdly, eccentric lesions had a greater luminal gain with predilatation stenting 


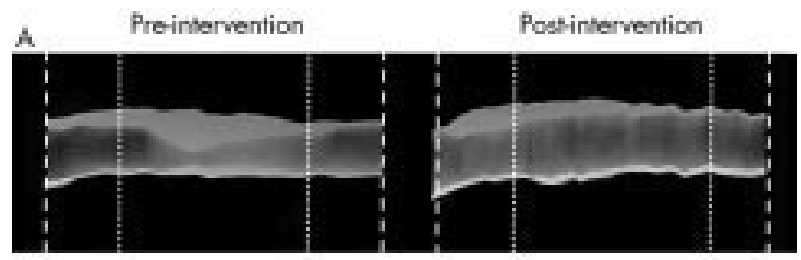

B

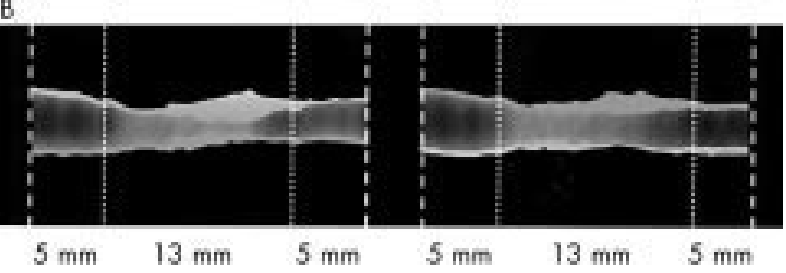

Figure 3 Example of three dimensional IVUS representations of plaque changes before and after intervention (during direct stenting). (A) Plaque with pre-intervention positive remodelling (ratio $=+16 \%$ ), the post-intervention changes in lumen, vessel (external elastic membrane $(E E M))$, and plaque (plaque + media $(P+M))$ volumes are $127 \mathrm{~mm}^{3}, 118 \mathrm{~mm}^{3},-9 \mathrm{~mm}^{3}$. The post-intervention remodelling ratio is $+27 \%$. The mean diameter of the coronary artery is $4.3 \mathrm{~mm}$.

(B) Plaque with pre-intervention negative remodelling (ratio $=-30 \%$ ), the post-intervention changes in lumen, EEM, and $P+M$ volumes are $45 \mathrm{~mm}^{3}, 33 \mathrm{~mm}^{3},-12 \mathrm{~mm}^{3}$. The post-intervention remodelling ratio is $-22 \%$. The mean diameter of the coronary artery is $3.2 \mathrm{~mm}$.

owing to larger vessel expansion. Finally, plaque composition influenced the mechanism of luminal gain with both predilatation stenting and direct stenting (plaque reduction with soft plaques during direct stenting, and vessel enlargement with dense plaques during predilatation stenting).

\section{Procedures}

There was a higher maximum balloon inflation pressure and fewer balloon inflations with direct stenting. In both groups, the vessel overstretch characterised by the stent to artery ratio was similar.

\section{Overall mechanisms of lumen enlargement}

Mechanisms of lumen enlargement in our study were similar with both types of stenting, with the same degree of plaque reduction $(\Delta \mathrm{P}+\mathrm{M}$ volume decrease $)$ and vessel expansion ( $\triangle$ EEM volume increase). Plaque reduction has two components: plaque compression and plaque embolisation. It is impossible to differentiate the individual contributions of these two factors. The mechanisms during stent implantation have been reported using planar IVUS analysis. ${ }^{15}$

\section{Influence of arterial remodelling}

Von Birgelen and colleagues showed that pre-intervention lesion remodelling has an impact on the operative mechanisms of balloon optimised directional coronary atherectomy procedures. ${ }^{16}$ While pre-intervention lesion remodelling has no influence on predilatation stenting, coronary lesions with positive remodelling treated by direct stenting appear to have a greater acute luminal gain than negatively modelled lesions. This luminal gain is caused by a greater vessel expansion, a mechanism not seen in the predilatation stenting group. Direct stenting has several procedural characteristics different from predilatation stenting: balloon inflation pressure is greater than $2.7 \mathrm{~atm}$ mean, and the number of inflations is less. In direct stenting, positive remodelling causes a greater acute luminal gain owing to a significant increase in vessel stretch. This vessel stretch increases the lesion to reference EEM post-stent implantation ratio, which is positive. This phenomenon accounts for the lack of EEM changes between ratios before and after the procedure.

The fact that the pre-intervention remodelling ratio remains constant after stent implantation can be explained by the main mechanism of lumen enlargement-that is, vessel expansion (positive remodelling) or plaque reduction (negative remodelling). In our study, the main operational mechanism in the direct stenting group was a significantly greater vessel expansion. In the predilatation stenting group, the post-intervention remodelling ratio was neutralised. In order to neutralise the positive remodelling, there must theoretically be plaque reduction, which would allow both lumen enlargement and a decrease in vessel size. In order to neutralise negative remodelling, there must be vessel expansion, which would allow both lumen enlargement and vessel enlargement. In our study, two mechanisms of lumen enlargement occurred in the predilatation stenting groupvessel expansion and plaque reduction.

An important additional difference between the two types of intervention is the arterial elastic recoil, more precisely termed the viscoelastic recoil. The arterial elastic recoil of approximately $30 \%$ seen after balloon angioplasty is neutralised by stent implantation. ${ }^{17}$ In these cases, the only operational recoil mechanism pertains to the intrinsic properties of the material used (316L stainless steel), and is 3.43 $(0.64) \%$ in MultiLink Duet and Tristar stents. ${ }^{18}$ A relation between arterial elastic recoil and stent to artery ratio has been reported after balloon angioplasty. ${ }^{3}$ Pasterkamp and colleagues showed that the use of an oversized balloon in cases of negative remodelling in the femoral artery may lead to a larger immediate gain, whereas in arteries with positive remodelling it might simply cause a greater amount of recoil. ${ }^{1}$ Stenting neutralises this arterial elastic recoil in cases of positive remodelling, a fact explained by the preponderance of vessel expansion over plaque reduction in direct stenting.

\section{Influence of lesion eccentricity}

In atherosclerotic arterial lesions, the degree of eccentricity of the plaque has been shown to influence the mechanisms of lumen enlargement during balloon angioplasty because of its effect on vessel stretch. ${ }^{19}$ Baptista and colleagues showed that the mechanism of vessel expansion is greater in eccentric lesions, similar to our findings in direct stenting. While these investigators found that the amount of plaque reduction increased in concentric lesions (without a disease-free wall), we did not find that eccentric or concentric lesions influenced plaque reduction.

\section{Influence of plaque composition}

In previous reports of predilatation stenting, calcification has been shown to inhibit full stent expansion. Nevertheless, calcified plaques were excluded in our study for two reasons: firstly, they are a serious acoustic limitation for image quantification, especially when the arc is greater than $45^{\circ}$; secondly, the safety and efficacy of direct stenting has been shown only in carefully selected populations with uncalcified lesions. ${ }^{4}$ In the direct stenting group, "soft" plaques (echolucent and rich in cells and extracellular lipid) were associated with a greater luminal gain owing to greater plaque reduction. In the predilatation stenting group, plaque morphology did not influence lumen gain. However, predilatation stenting of dense plaques resulted in a greater vessel expansion and less plaque reduction. This is consistent with the known biomechanical characteristics of soft plaques, which include a lower elasticity modulus (Young's modulus) allowing the generation of greater strain for a given stress magnitude, and a consistency that allows potential plaque fragmentation and embolisation..$^{20}$

\section{Study limitations}

Qualitative assessment of atheromatous plaque composition in coronary arteries is known to be subjective and is based an experienced operator's interpretation. We based our work on the European Society of Cardiology classification, as described 
by Di Mario and colleagues. ${ }^{14}$ This classification has recently been shown to have good reproducibility and to be highly correlated with histological findings in an in vitro study. ${ }^{22}$

The assessment of the relative importance of positive or negative remodelling is dependent on the definition used, and different definitions could lead to different results. ${ }^{23}$

The potential advantage of using the same stent design in order to reduce the variability of the volumetric IVUS methodology can also be a limitation. Mechanisms of lumen enlargement may be different with different stent designs. ${ }^{18}{ }^{24}$ The Duet stent delivery system used long balloon shoulders outside the stent and was different from the Tristar stent delivery system.

The lesions were not calcified, so no conclusions about plaque calcification can be drawn. However, direct stenting is generally dedicated to non-calcified lesions and this criterion was applied to both groups.

We measured $5 \mathrm{~mm}$ long reference segments on either side of the stent and showed the first and last $1 \mathrm{~mm}$ long volumes undergo significant change, so changes further from the stent are possible.

\section{Authors' affiliations}

G Finet, N J Weissman, G S Mintz, L F Satler, K M Kent, J R Laird, G A Adelmann, A E Ajani, M T Castagna, G Rioufol, A D Pichard, Intravascular Ultrasound Imaging and Cardiac Catheterization Laboratories, Cardiovascular Research Institute, Washington Hospital Center, Washington DC, USA

\section{REFERENCES}

1 Pasterkamp G, Borst C, Gussenhoven EJ, et al. Reremodeling of de novo atherosclerotic lesions in femoral arteries: impact on mechanism of balloon angioplasty. J Am Coll Cardiol 1995;26:422-8.

2 Honye J, Mahon DJ, Jain A, et al. Morphological effects of coronary balloon angioplasty in vivo assessed by intravascular ultrasound imaging. Circulation 1992;85:1012-25.

3 Timmis SBH, Burns WJ, Hermiller JB, et al. Influence of coronary atherosclerotic remodeling on the mechanism of balloon angioplasty. Am Heart J 1997;134:1099-106.

4 Pentousis D, Guerin Y, Funck F, et al. Direct stent implantation without predilation using the multilink stent. Am J Cardiol 1998;82:1437-40.

5 Ormiston JA, Webster MWI, Ruygrok PN, et al. A randomized study of direct coronary stent delivery with stenting after predilation: the NIR future trail. Cathet Cardiovasc Intervent 2000;50:377-81.

6 Herz I, Assali A, Solodsky A, et al. Coronary stenting without predilation (SWOP): applicable technique in everyday practice. Cathet Cardiovasc Intervent 1999:48:123-9.
7 Heldman AW, Brinker JA. Direct stenting: is the future near? Cathet Cardiovasc Intervent 1999;48:123-9.

8 Finet G, Maurincomme E, Tabib A, et al. Artifacts in intravascular ultrasound imaging: analyses and implications. Ultrasound Med Biol 1993; 19:533-47.

9 Finet G, Cachard C, Delachartre P, et al. Artifacts in intravascular ultrasound imaging during coronary artery stent implantation. Ultrasound Med Biol 1998:24:793-802.

10 Finet G, Maurincomme E, Reiber JH, et al. Evaluation of an automatic intraluminal edge detection technique for intravascular ultrasound images. Japanese Circ J 1997:62:1 17-25.

11 Weissman NJ, Palacios IF, Weyman AE. Dynamic expansion of the coronary arteries: implications for intravascular ultrasound measurements. Am heart J 1995; 130:46-51

12 FuessI RT, Mintz GS, Pichard AD, et al. In vivo validation of intravascular ultrasound length measurements using a motorized transducer pullback device. Am J Cardiol 1996;77:1115-18.

13 Nishimura RA, Edwards WD, Warnes CA, et al. Intravascular ultrasound imaging: in vitro validation and pathological correlation. J Am Coll Cardiol 1990;16:145-54.

14 Di Mario C, Gorge G, Peters R, et al. Clinical application and image interpretation in intracoronary ultrasound. Eur Heart J 1998;19:207-29.

15 Ahmed JM, Mintz GS, Weissman NJ, et al. Mechanisms of lumen enlargement during intracoronary stent implantation: an intravascular ultrasound study. Circulation 2000;102:7-10.

16 von Birgelen C, Mintz GS, de Vrey EA, et al. Preintervention lesion remodelling affects operative mechanisms of balloon optimised directional coronary atherectomy procedures: a volumetric study with three dimensional intravascular ultrasound. Heart 2000;83:192-7.

17 Haude D, Erbel R, Issa H, et al. Quantitative analysis of elastic recoil after balloon angioplasty and after intracoronary implantation of balloon-expandable Palmaz-Schatz stents. J Am Coll Cardiol 1993;21:26-34.

18 Barragan P, Rieu R, Garitey V et al. Elastic recoil of coronary stents: a comparative analysis. Cathet Cardiovasc Intervent 2000;50:112-19.

19 Baptista J, Umans VA, DiMario C, et al. Mechanisms of luminal enlargement and quantification of vessel wall trauma following balloon coronary angioplasty and directional atherectomy: a study using intracoronary ultrasound, angioscopy and angiography. Eur Heart J 1995; 16:1603-12

20 Lee RT, Loree HM, Cheng GC, et al. Computational structural analysis based on intravascular ultrasound imaging before in vitro angioplasty: prediction of plaque fracture locations. J Am Coll Cardiol 1993;21:777-82

21 Fuster V, Badimon L, Badimon J, et al. The pathogenesis of coronary artery disease and the acute coronary syndromes. N Engl J Med 1992:326:310-18.

22 Palmer ND, Northridge D, Lessells A, et al. In vitro analysis of coronary atheromatous lesions by intravascular ultrasound. Eur Heart J 1999:20:1701-6.

23 Nishioka T, Berglund $H$, Luo $H$, et al. How should we define inadequate coronary arterial remodeling? Circulation 1998;97:1424-5.

24 Rieu R, Barragan P, Masson C, et al. Radial force of coronary stents: a comparative analysis. Cathet Cardiovasc Intervent 1999;46:380-91. 